\title{
The impact of different algorithms for ideal body weight on screening for hydroxychloroquine retinopathy in women
}

This article was published in the following Dove Press journal:

Clinical Ophthalmology

24 July 2014

Number of times this article has been viewed

\section{David J Browning \\ Chong Lee \\ David Rotberg}

Charlotte Eye, Ear, Nose and Throat Associates, Charlotte, North Carolina, NC, USA
Correspondence: David J Browning Charlotte Eye, Ear, Nose and Throat Associates, 6035 Fairview Road, Charlotte, NC 28210, USA

$\mathrm{Tel}+\mathrm{I} 7042953180$

Fax +l 7042953186

Email dbrowning@ceenta.com
Purpose: To determine how algorithms for ideal body weight (IBW) affect hydroxychloroquine dosing in women.

Methods: This was a retrospective study of 520 patients screened for hydroxychloroquine retinopathy. Charts were reviewed for sex, height, weight, and daily dose. The outcome measures were ranges of IBW across algorithms; rates of potentially toxic dosing; height thresholds below which $400 \mathrm{mg} / \mathrm{d}$ dosing is potentially toxic; and rates for which actual body weight (ABW) was less than IBW.

Results: Women made up 474 (91\%) of the patients. The IBWs for a height varied from 30-34 pounds (13.6-15.5 kg) across algorithms. The threshold heights below which toxic dosing occurred varied from $62-70$ inches $(157.5-177.8 \mathrm{~cm})$. Different algorithms placed $16 \%-98 \%$ of women in the toxic dosing range. The proportion for whom dosing should have been based on $\mathrm{ABW}$ rather than IBW ranged from 5\%-31\% across algorithms.

Conclusion: Although hydroxychloroquine dosing should be based on the lesser of $\mathrm{ABW}$ and IBW, there is no consensus about the definition of IBW. The Michaelides algorithm is associated with the most frequent need to adjust dosing; the Metropolitan Life Insurance, large frame, mean value table with the least frequent need. No evidence indicates that one algorithm is superior to others.

Keywords: hydroxychloroquine, ideal body weight, actual body weight, toxicity, retinopathy, algorithms

\section{Introduction}

Hydroxychloroquine retinopathy was once considered to be rare with only 47 cases reported between 1960 and 2005. ${ }^{1}$ Since that era, increased awareness of the problem and more sensitive methods of detection have suggested that toxicity is not as rare as previously thought. ${ }^{2,3}$ Failure analyses have identified overdosing of patients as the main cause of retinopathy. ${ }^{4,5}$ Retinopathy is rare if dosing is kept below $6.5 \mathrm{mg} / \mathrm{kg}$ of IBW, but in practice approximately $12 \%-56 \%$ of patients in the US are overdosed. ${ }^{3,6,7}$ As a result, increased attention has been focused on assessing the toxicity of daily dosing among screened patients, rather than just detecting retinopathy at the earliest stage possible.

Doing so requires a concept of IBW (synonyms include lean body weight and top normal body weight). ${ }^{8-12}$ The importance of the concept arises from the preferential partitioning of hydroxychloroquine into lean tissue and away from fat. ${ }^{9,11,13,14}$ In ophthalmic case series, various tables and formulas for IBW have been used., ${ }^{2,-10,15-20}$ Clinically important implications for the screening ophthalmologist, not previously investigated, arise from these different definitions of IBW. 
Short, obese patients have long been recognized as being at increased risk for hydroxychloroquine retinopathy. ${ }^{9,11,21}$ In these patients the need to use ideal rather than actual body weight $(\mathrm{ABW})$ to assess daily dosing has been publicized, but incompletely adopted. ${ }^{21}$ Emphasis has also been placed on ABW rather than IBW for persons of asthenic build. ${ }^{6}$ For this phenotype, use of a larger value for IBW based on height, rather than the smaller $\mathrm{ABW}$, could lead to toxic dosing. ${ }^{6}$

In this report the different algorithms in use are compared for their potential effects on screening. From this analysis, an argument is presented in favor of a preferred algorithm for use by clinicians in daily practice.

\section{Methods}

Articles concerning chloroquine and hydroxychloroquine retinopathy that refer to IBW, lean body weight, or top normal body weight based on height, actual weight, and sex were collected and the algorithms contained were used to create a spreadsheet of IBW versus height for a range of commonly encountered heights. Because greater than $95 \%$ of cases of hydroxychloroquine retinopathy have been reported in women, only algorithms for women were considered when versions differentiating sex existed. ${ }^{13,5,8,9,13,20,22-39}$ Algorithms that do not distinguish between sexes were also included. ${ }^{10}$

In this work, potentially toxic dosing refers to doses $>6.5 \mathrm{mg} / \mathrm{kg} / \mathrm{d}$, not because lower doses cannot be associated with hydroxychloroquine retinopathy, but because of the acknowledged higher risk of doses in this range. ${ }^{4,9,40,41}$

The electronic medical records of a consecutive series of 520 patients screened for hydroxychloroquine retinopathy in a practice of 26 ophthalmologists and three optometrists were retrospectively examined. Of these 520 records, the $474(91 \%)$ pertaining to women were selected for analysis. Data were extracted on daily dosing, ABW, and IBW based on height using the algorithms. Height and weight were selfreported. Descriptive statistics were computed with JMP 4.0 software (SAS Institute Inc., Cary, NC, USA). Waiver of informed consent and waiver of Health Information Portability and Accountability Act authorization were approved by the Presbyterian Hospital Institutional Review Board.

\section{Results}

Seven algorithms used by ophthalmologists in screening for chloroquine and hydroxychloroquine retinopathy are listed in Table 1. Of the 474 women screened for hydroxychloroquine retinopathy, determinations of height, weight, and daily dose of drug were made in 269 (57\%), 241 (51\%), and 325 (69\%), respectively. The distributions of height and weight are
Table I Algorithms for ideal body weight

\begin{tabular}{|c|c|c|}
\hline Name & Formula & Reference \\
\hline Wolfe & $Y=5.07 X-203.9$ & 2 \\
\hline Michaelides* & $Y=3.78 X-129.9$ & 8 \\
\hline $\begin{array}{l}\text { Metropolitan Life Insurance small } \\
\text { frame mean value table }\end{array}$ & $Y=3 X-7 \mid$ & 9,15 \\
\hline $\begin{array}{l}\text { Metropolitan Life Insurance large } \\
\text { frame mean value table }\end{array}$ & $Y=3.3 X-68.9$ & 9,15 \\
\hline NHLBI table & $Y=4.28 X-134.32$ & 10 \\
\hline Bergholz & $Y=2.16 X-0.85$ & 16 \\
\hline Walvick ${ }^{\mp}$ & $Y=3.5 X-96$ & 7 \\
\hline
\end{tabular}

Notes: $Y$, ideal body weight in pounds. $X$, height in inches. *This formula depends on actual body weight at the specified height, which was taken as the mean value for patients of that height taking hydroxychloroquine in the authors' series. ${ }^{\mp} T h i s$ formula assumes that at a height of 60 inches, the ideal body weight was 114 pounds, which is the midpoint of the values of all the other algorithms. The formulas apply across a range of heights from 60 to 74 inches. When an algorithm was given as a table in the reference, the least squares best fit line to the tabulated data was used as the formula.

Abbreviation: NHLBI, National Heart Lung and Blood Institute.

shown in Figures 1 and 2. The median height was 64 inches $(162.6 \mathrm{~cm})$, interquartile range (IQR) $(62,66$ inches), range (57, 74 inches). The median weight was 160 pounds $(72.7 \mathrm{~kg})$, IQR (133, 185 pounds), range (90, 330 pounds). Twenty-nine percent of women were less than or equal to 63 inches tall $(160 \mathrm{~cm})$, a threshold height for potentially toxic dosing based on consumption of $400 \mathrm{mg}$ hydroxychloroquine per day and a commonly used IBW algorithm. ${ }^{10}$ Twenty-seven percent of women weighed less than or equal to 135 pounds $(61.4 \mathrm{~kg})$, a threshold IBW for potentially toxic dosing based on consumption of 400 hydroxychloroquine per day. The daily doses used in order of frequency were $400 \mathrm{mg}$ (192, 59.1\%), $200 \mathrm{mg}(106,32.6 \%), 300 \mathrm{mg}(25,7.7 \%)$, $600 \mathrm{mg}(1,0.3 \%)$, and $150 \mathrm{mg}(1,0.3 \%)$. Of the 474 patients screened, 7 (1.5\%) had hydroxychloroquine retinopathy.

Figure 3 shows the IBWs as a function of height for the seven algorithms. At heights for which toxic dosing is an issue (less than 5 feet 10 inches) $(177.8 \mathrm{~cm}$ ), the associated IBWs

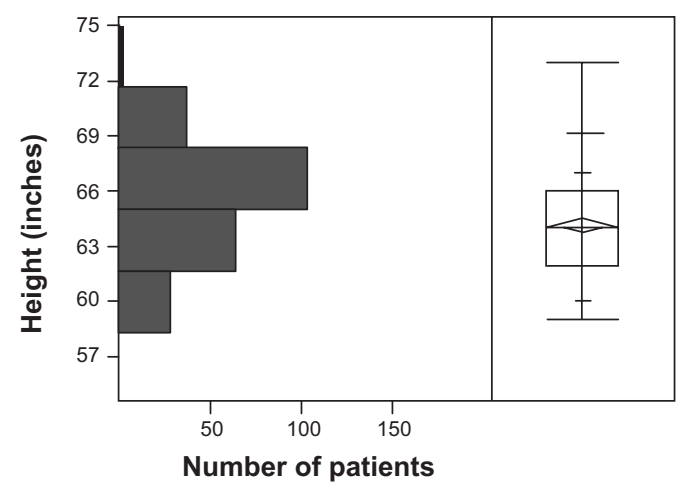

Figure I Distribution of heights of 269 women taking hydroxychloroquine. 


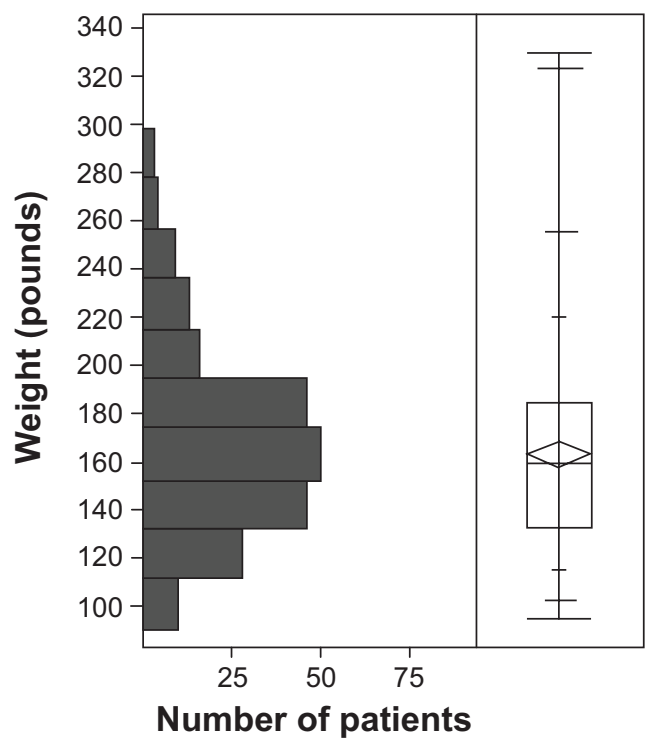

Figure 2 Distribution of actual weights of 24 I women taking hydroxychloroquine.

across algorithms vary from 30-32 pounds (13.6-14.5 kg) with the most common spread being 31 pounds $(14.1 \mathrm{~kg})$.

Table 2 shows the IBWs as a function of height for women. Table 3 shows the same information in metric units. Each row represents a different algorithm or table in the ophthalmic literature. Most patients are prescribed a dose of hydroxychloroquine of $400 \mathrm{mg} / \mathrm{d}$. This will be a potentially toxic dose for women with an IBW of 135 pounds $(61.4 \mathrm{~kg})$ or less. Table 2 shows that the threshold height for toxicity varies between 5 feet 2 inches $(157.5 \mathrm{~cm})$ and 5 feet 10 inches $(177.8 \mathrm{~cm})$, depending on the algorithm used. The most conservative algorithm is the Michaelides algorithm and the most liberal is the algorithm from the Metropolitan Life Insurance company table for women of large frame using the mean values. The percentages of patients with heights less than or equal to the height thresholds for toxicity by algorithm ranged from $16 \%-98 \%$.

Table 2 also shows that the percentage of patients in whom ABW is less than IBW varies depending on the IBW algorithm used. The least strict algorithm (Metropolitan Life table for women, large frame, mean value algorithm) places $31 \%$ of patients in a situation in which ABW should be used for dosing rather than IBW. The strictest algorithm (Michaelides) places $5 \%$ of patients in this situation.

\section{Discussion}

Hydroxychloroquine retinopathy is a problem that predominantly affects women. Greater than $95 \%$ of reported cases of hydroxychloroquine retinopathy in the literature have been in women. ${ }^{1,3,5,8,13,20,22-39}$ Three factors account for this sex dichotomy. First, women are predominantly affected by the autoimmune diseases for which hydroxychloroquine is prescribed. In the present series, $92 \%$ of patients screened were women. Secondly, the distribution of heights and weights for men is shifted to the right compared to women. In the US, the median height for men is approximately 5 inches $(12.7 \mathrm{~cm})$ taller than women.$^{42}$ Lastly, in sex specific algorithms, for any height, the IBW for men is greater than for women. In the study population, $29 \%$ of women but only $5 \%$ of men fell below the 5 foot 3 inch $(160 \mathrm{~cm})$ threshold for toxic dosing of hydroxychloroquine at the most common

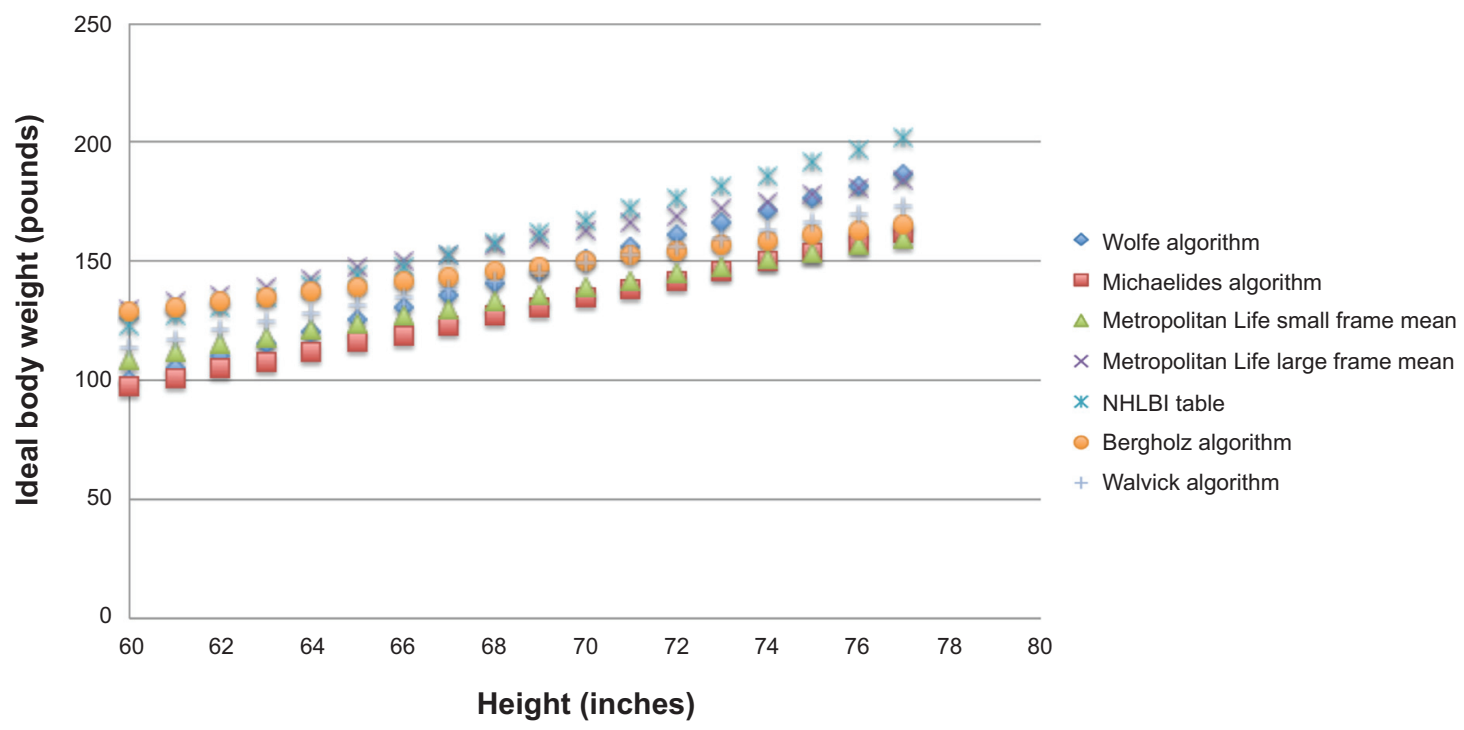

Figure 3 Graphs of ideal body weight versus height for seven algorithms used in ophthalmology publications concerning screening for hydroxychloroquine retinopathy. Abbreviation: NHLBI, National Heart Lung and Blood Institute. 

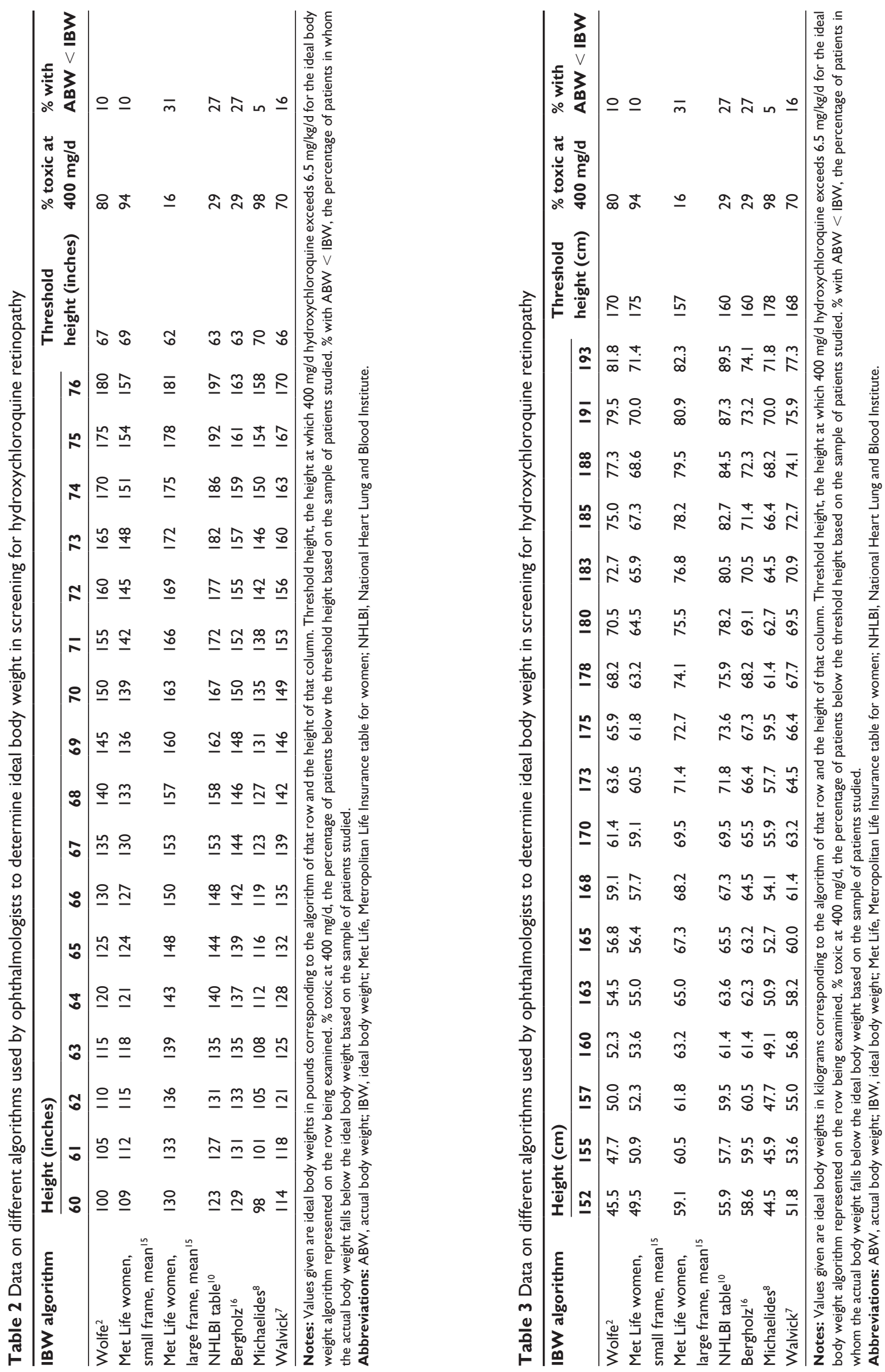
daily dose of $400 \mathrm{mg} / \mathrm{d}$ using the National Heart Lung and Blood Institute (NHLBI) algorithm for IBW.

The risk factors for hydroxychloroquine retinopathy include daily dose adjusted for the lesser of IBW and ABW, cumulative dose, age, pre-existing maculopathy, renal insufficiency, and hepatic insufficiency. ${ }^{8,40}$ If the ABW is greater than the IBW, daily dose should be adjusted for IBW, which depends on height. ${ }^{1,4}$ If the ABW is less than or equal to the IBW, then the daily dose should be adjusted for ABW, not the IBW. ${ }^{6}$ Of the acknowledged risk factors for hydroxychloroquine retinopathy, adjusted daily dose is the most important risk factor, because it is the only one that can be changed. ${ }^{6}$ Consequently, IBW deserves scrutiny although many publications have only considered $\mathrm{ABW}^{43}$

However, in the ophthalmic literature, there is no consensus about the best algorithm, and at least seven have been used in publications. Some formulas include a dependence on sex, $\mathrm{ABW}$, or somatotype (small, medium, or large build), but many do not. ${ }^{2,8-10,15,17}$ All of the algorithms depend on height. The literature is confusing in its use of the terms ideal, lean, and top normal body weight. Most use the terms interchangeably as synonyms. ${ }^{9,11,12}$ Some, however, distinguish lean from IBW, in which case lean body weight is lower.

Which algorithm the ophthalmologist chooses to use will affect thresholds for ascertaining potentially toxic daily dosing. Choosing the Michaelides algorithm will lead to $98 \%$ of patients taking the most common daily dose of $400 \mathrm{mg} / \mathrm{d}$ to be classified as taking a potentially toxic dose. In contrast, if the Metropolitan Life Insurance table for large frame women, mean values is chosen, $16 \%$ of patients will be classified as taking a potentially toxic dose. It seems impractical to expect that ophthalmologists will contact prescribing physicians to alter dosing in greater than $50 \%$ of the patients that they screen. A less strict threshold, eg, exemplified by the Bergholz algorithm or the NHLBI table, balances concern to prevent toxicity with the practical reality that a minority of patients treated with hydroxychloroquine require dosage modification based on concerns regarding ophthalmic toxicity. Although the Wolfe algorithm has been advocated in one editorial, there was no basis given for the preference, and there are reasons why it is not preferable. ${ }^{44,45}$

In addition, it is important not to overlook the ABW of the patient. If the ABW is less than the IBW, it is the ABW that should be used in assessing whether daily dosing is potentially toxic. ${ }^{6}$ If one uses an algorithm that yields a smaller IBW at a given height, there will be fewer patients in whom a concern exists that $\mathrm{ABW}$ is less than IBW. The trade-off, however, is that one will have a higher proportion of patients who are overdosed at the typical dosage range of $400 \mathrm{mg} / \mathrm{d}$.

The commonly quoted threshold of $6.5 \mathrm{mg} / \mathrm{kg} / \mathrm{d}$ was originally published as the upper limit of safe dosing by Mackenzie, because in his experience with $>900$ patients he had never witnessed toxicity if dosing based on ABW stayed below this level. ${ }^{9} \mathrm{He}$ also reported the mean daily dosing based on $\mathrm{ABW}$ in eight patients taking hydroxychloroquine who developed retinopathy. This value was $7.77 \mathrm{mg} / \mathrm{kg} / \mathrm{d} .{ }^{9} \mathrm{He}$ then weighed 544 women with rheumatoid arthritis and reported that $14 \%$ of them, given the usual $400 \mathrm{mg} / \mathrm{d}$ dose of hydroxychloroquine, would exceed the toxic dose threshold based on ABW. ${ }^{9}$ The ABW below which usual dosing of $400 \mathrm{mg} / \mathrm{d}$ would exceed this toxic threshold was therefore 114.3 pounds $(52.0 \mathrm{~kg})$. In our data set, using this ABW cut-off point, $8.3 \%$ of women exceeded this toxic threshold. However, since Mackenzie's time, there have now been multiple reported cases of hydroxychloroquine retinopathy in patients who developed retinopathy despite taking less than $6.5 \mathrm{mg} / \mathrm{kg} / \mathrm{d}$ based on IBW, not ABW., ${ }^{4,7,30,31,33}$ Therefore, $6.5 \mathrm{mg} / \mathrm{kg} / \mathrm{d}$ based on IBW has been transformed from the threshold for safe dosing to the threshold for toxic dosing. Mackenzie's own toxic threshold based on IBW, $8.39 \mathrm{mg} / \mathrm{kg} / \mathrm{d}$, is now considered to be set too high. ${ }^{9}$ That is, the daily dosing threshold for toxicity has been lowered as more experience has been gained.

This study has limitations. Not all algorithms for IBW were included in the analysis and men were not analyzed. Algorithms not published in the ophthalmic literature were excluded. This should not be a major drawback in practice. No case of hydroxychloroquine retinopathy in a man was reported in a review of 47 cases from $1960-2005 .{ }^{13}$ The statistics for prevalence of potentially toxic dosing using the various algorithms were derived from retrospectively collected data at a single center. They were in broad agreement with earlier published statistics from a separate center. ${ }^{9}$ It is possible that a broader sample of centers, and prospectively collected data, would lead to different outcomes. However, even if the actual outcomes were to differ, the nature of the analysis would not, and the issues raised herein are clinically important and previously unaddressed. Until prospectively collected multicenter data are gathered, the concepts discussed here may be useful to clinicians screening for hydroxychloroquine retinopathy, and may reduce the incidence of this frequently preventable iatrogenic condition. 


\section{Disclosure}

None of the authors has any proprietary interest in any product described herein. No grant funding was used in this research. Submitted for presentation at the annual meeting of the American Ophthalmological Society, May 2014, 15-18, New York, USA. The authors report no further conflicts of interest in this work.

\section{References}

1. Payne JF, Hubbard GB III, Aaberg TM Sr, Yan J. Clinical characteristics of hydroxychloroquine retinopathy. Br J Ophthalmol. 2011;95(2): 245-250.

2. Wolfe F, Marmor MF. Rates and predictors of hydroxychloroquine retinal toxicity in patients with rheumatoid arthritis and systemic lupus erythematosus. Arthritis Care Res (Hoboken). 2010;62(6): 775-784.

3. Levy GD, Munz SJ, Paschal J, Cohen HB, Prince KJ, Peterson T. Incidence of hydroxychloroquine retinopathy in 1,207 patients in a large multicenter outpatient practice. Arthritis Rheum. 1997;40(8): $1482-1486$

4. Browning DJ. Hydroxychloroquine and Chloroquine Retinopathy: Screening for Drug Toxicity. Am J Ophthalmol. 2002;133(5):649-656.

5. Marmor MF. Comparison of screening procedures in hydroxychloroquine toxicity. Arch Ophthalmol. 2012;130(4):461-469.

6. Browning DJ. Impact of the revised American academy of ophthalmology guidelines regarding hydroxychloroquine screening on actual practice. Am J Ophthalmol. 2013;155(3):418-428.

7. Walvick MD, Walvick MP, Tongson E, Ngo CH. Hydroxychloroquine: lean body weight dosing. Ophthalmology. 2011;118(10):2100.

8. Michaelides M, Stover NB, Francis PJ, Weleber RG. Retinal toxicity associated with hydroxychloroquine and chloroquine: risk factors, screening, and progression despite cessation of therapy. Arch Ophthalmol. 2011;129(1):30-39.

9. Mackenzie AH. Dose refinements in long-term therapy of rheumatoid arthritis with antimalarials. Am J Med. 1983;75(1A):40-45.

10. Browning DJ. Reply to Defining Ideal Body Weight. Am J Ophthalmol. 2002;134(6):935-936.

11. Bernstein HN. Ocular safety of hydroxychloroquine sulfate (Plaquenil). South Med J. 1992;85(3):274-279.

12. Pai MP, Paloucek FP. The origin of the "Ideal" body weight equations. Ann Pharmacother. 2000;34(9):1066-1069.

13. Yam JC, Kwok AK. Ocular toxicity of hydroxychloroquine. Hong Kong Med J. 2006;12(4):294-304.

14. Sundelin SP, Terman A. Different effects of chloroquine and hydroxychloroquine on lysosomal function in cultured retinal pigment epithelial cells. APMIS. 2002;110(6):481-489.

15. Johnson MW, Vine AK. Hydroxychloroquine therapy in massive total doses without retinal toxicity. Am J Ophthalmol. 1987;104(2): 139-144.

16. Bergholz R, Schroeter J, Ruther K. Evaluation of risk factors for retinal damage due to chloroquine and hydroxychloroquine. Br JOphthalmol. 2010;94(12):1637-1642.

17. Nowaczyk P, Murawa D, Polom K, et al. Analysis of sentinel lymph node biopsy results in colon cancer in regard of the anthropometric features of the population and body composition assessment formulas. Langenbecks Arch Surg. 2012;397(5):779-786.

18. Shah B, Sucher K, Hollenbeck CB. Comparison of ideal body weight equations and published height-weight tables with body mass index tables for healthy adults in the United States. Nutr Clin Pract. 2006; 21(3):312-319.

19. Schwartz SG, Mieler WF. Retinal and Choroidal Manifestations of Systemic Medications. In: Arevalo JF, editor. Retinal and Choroidal Manifestations of Selected Systemic Diseases. New York: Springer; 2013:479-492.
20. Fung AE, Samy CN, Rosenfeld PJ. Optical coherence tomography findings in hydroxychloroquine and chloroquine-associated maculopathy. Retinal Cases and Brief Reports. 2007;1(3):128-130.

21. Marmor MF, Carr RE, Easterbrook M, et al. Recommendations on screening for chloroquine and hydroxychloroquine retinopathy. Ophthalmology. 2002;109(7):1377-1382.

22. Stepien KE, Han DP, Schell J, Godara P, Rha J, Carroll J. Spectraldomain optical coherence tomography and adaptive optics may detect hydroxychloroquine retinal toxicity before symptomatic vision loss. Trans Am Ophthalmol Soc. 2009;107:28-34.

23. Elder M, Rahman AM, McLay J. Early paracentral visual field loss in patients taking hydroxychloroquine. Arch Ophthalmol. 2006; 124(12):1729-1733.

24. Mavrikakis I, Sfikakis PP, Mavrikakis E, et al. The incidence of irreversible retinal toxicity in patients treated with hydroxychloroquine a reappraisal. Ophthalmology. 2003;110(7):1321-1326.

25. Mavrikakis M, Papazoglou S, Sfikakis PP, Vaiopoulos G, Rougas K. Retinal toxicity in long term hydroxychloroquine treatment. Ann Rheum Dis. 1996;55(3):187-189.

26. Anderson C, Blaha GR, Marx JL. Humphrey visual field findings in hydroxychloroquine toxicity. Eye (Lond). 2011;25(12):1535-1545.

27. Thorne JE, Maguire AM. Retinopathy after long term, standard doses of hydroxychloroquine. Br J Ophthalmol. 1999;83(10): 1201-1202.

28. Teoh SC, Lim J, Koh A, Lim T, Fu E. Abnormalities on the multifocal electroretinogram may precede clinical signs of hydroxychloroquine retinotoxicity. Eye (Lond). 2006;20(1):129-132.

29. Anderson C, Pahk P, Blaha GR, et al. Preferential hyperacuity perimetry to detect hydroxychloroquine retinal toxicity. Retina. 2009;29(8): $1188-1192$.

30. Falcone PM, Paolini L, Lou PL. Hydroxychloroquine toxicity despite normal dose therapy. Ann Ophthalmol. 1993;25(10):385-388.

31. Bienfang D, Coblyn JS, Liang MH, Corzillius M. Hydroxychloroquine retinopathy despite regular ophthalmologic evaluation: a consecutive series. J Rheumatol. 2000;27(11):2703-2706.

32. Warner AE. Early hydroxychloroquine macular toxicity. Arthritis Rheum. 2001;44(8):1959-1961.

33. Weiner A, Sandberg MA, Gaudio AR, Kini MM, Berson EL. Hydroxychloroquine retinopathy. Am J Ophthalmol. 1991;112(5): 528-534.

34. Kellner S, Weinitz S, Kellner U. Spectral domain optical coherence tomography detects early stages of chloroquine retinopathy similar to multifocal electroretinography, fundus autofluorescence and near-infrared autofluorescence. Br J Ophthalmol. 2009;93(11): 1444-1447.

35. Kellner U, Renner AB, Tillack H. Fundus autofluorescence and mfERG for early detection of retinal alterations in patients using chloroquine/hydroxychloroquine. Invest Ophthalmol Vis Sci. 2006;47(8):3531-3538.

36. Chen E, Brown DM, Benz MS, et al. Spectral domain optical coherence tomography as an effective screening test for hydroxychloroquine retinopathy (the "flying saucer" sign). Clin Ophthalmol. 2010;4: 1151-1158.

37. Rodriguez-Padilla JA, Hedges TR III, Monson B, et al. High-speed ultrahigh-resolution optical coherence tomography findings in hydroxychloroquine retinopathy. Arch Ophthalmol. 2007;125(6):775-780.

38. Kelmenson AT, Brar VS, Murthy RK, Chalam KV. Fundus autofluorescence and spectral domain optical coherence tomography in early detection of Plaquenil maculopathy. Eur J Ophthalmology. 2010;20(4): 785-788.

39. Reed H, Karlinsky W. Delayed onset of chloroquine retinopathy. Can Med Assoc J. 1967;97(23):1408-1411.

40. Marmor MF, Kellner U, Lai TYY, Lyons JS, Mieler WF. American Academy of Ophthalmology. Revised recommendations on screening for chloroquine and hydroxychloroquine retinopathy. Ophthalmology. 2011;118(2):415-422. 
41. Bernstein HN. Ophthalmologic considerations and testing in patients receiving long-term antimalarial therapy. Am J Med. 1983;75(1A) 25-34.

42. McDowell MA, Fryar CD, Ogden CL, Flegal KM. National Health Statistics Reports. Anthropometric reference data for children and adults: United States 2003-2006; 2008. Available from: http://www. cdc.gov/nchs/data/nhsr/nhsr010.pdf. Accessed June 25, 2014.
43. Marmor MF. Efficient and effective screening for hydroxychloroquine toxicity. Am J Ophthalmol. 2013;155(3):413-414.

44. Browning DJ. Reply to Impact of the revised American Academy of Ophthalmology guidelines regarding hydroxychloroquine screening on actual practice. Am J Ophthalmol. 2013;156(2):410-411.

45. Browning DJ. Hydroxychloroquine and Chloroquine Retinopathy. First edition. New York, Springer; 2014.

\section{Publish your work in this journal}

Clinical Ophthalmology is an international, peer-reviewed journal covering all subspecialties within ophthalmology. Key topics include: Optometry; Visual science; Pharmacology and drug therapy in eye diseases; Basic Sciences; Primary and Secondary eye care; Patien Safety and Quality of Care Improvements. This journal is indexed on

Submit your manuscript here: http://www.dovepress.com/clinical-ophthalmology-journal

\section{Dovepress}

PubMed Central and CAS, and is the official journal of The Society of Clinical Ophthalmology (SCO). The manuscript management system is completely online and includes a very quick and fair peer-review system, which is all easy to use. Visit http://www.dovepress.com/ testimonials.php to read real quotes from published authors. 